\title{
Las armadas de Felipe IV. La conservación de la monarquía
}

\section{Philip IV's Armies. The conservation of the Monarchy}

\author{
CARLOS REMARTÍNEZ MARTÍNEZ \\ Universidad Autónoma de Madrid \\ carlos.remartinez@estudiante.uam.es
}

\begin{abstract}
Resumen: Tras realizar una visión general sobre libros, artículos y ponencias de las últimas décadas en historiografía naval, podemos observar como la situación del poder naval durante el reinado de Felipe IV se analizó desde diferentes perspectivas historiográficas, y como todas ellas nos ofrecen un conocimiento a día de hoy incompleto. A través de este artículo se pretende entender el mar como un espacio de unión entre los territorios del rey católico, aspecto vital para comprender la idea de "conservación" y "reputación" del Imperio. Conceptos de los que fueron conscientes los coetáneos y, por ello, su preocupación por mantener un sistema naval capaz de defender los territorios de la monarquía. Asimismo, a través del estudio de las armadas, analizaremos algunos factores de la compleja relación entre la Corte de Felipe IV y la Corona portuguesa.
\end{abstract}

Palabras clave: Historia Moderna, Monarquía Hispánica, armadas, conservación.

Abstract: After an overview of books, articles and presentations of recent decades in naval historiography, we can observe how the situation of naval power during the reign of Philip IV was analysed from different historiographic perspectives, and how all of them offer us an incomplete knowledge today. This article seeks to understand the sea as an area of union between the territories of the Catholic King, which constitutes avital aspect to understand the idea of conservation and reputation of the Empire. These are concepts of which the contemporaries were aware and, hence, their concern to maintain a naval system capable of defending the territories of the monarchy. In addition, through the study of the armed we will analyse some factors of the complex relationship between the Court of Philip IV and the Portuguese Crown.

Keywords: Early Modern History, Hispanic Monarchy, Armies, Conservation.

Recibido: 5 de diciembre de 2017; aceptado: 1 de junio de 2018; publicado: 27 de septiembre de 2018. Revista Historia Autónoma, 13 (2018), pp. 71-83

DOI: https://doi.org/10.15366/rha2018.13.004 


\section{Estado de la cuestión}

En el presente trabajo nos centraremos en cómo afectó la política del conde-duque de Olivares a las armadas de Felipe IV, destacando algunos espacios marítimos para comprender conceptos como "guerra preventiva", "reputación" y "conservación”. Asimismo, a través de la política naval de la monarquía intentaremos ahondar en la desconexión entre la Corte de Felipe IV y la élite portuguesa. Para ello, ha sido necesario descartar la explicación del funcionamiento de varias armadas, algunos sucesos bélicos y ciertos espacios como el mar Mediterráneo o las Filipinas, aspectos que, con fortuna, podremos englobar en próximos artículos.

Al realizar una visión general sobre libros, artículos y ponencias de las últimas décadas en historiografía naval, se observa una gran escasez de títulos, algo bien ejemplificado en la obra editada por Jeremy Black ${ }^{1}$, donde solo hay tres artículos sobre el mundo hispano realizados por hispanistas británicos (Irving A. A. Thompson, David Goodman y Robert Stradling)2

A comienzos de 1950, la historiografía militar sufrió una transformación debido a la escuela marxista británica de postguerra. Historiadores como Eric Hobsbawm, Perry Anderson, John H. Elliott o Edward Thompson planteaban un análisis histórico de gran alcance como la transición de la Antigüedad al capitalismo a través del feudalismo. La historiografía marxista se agrupó en la revista de mayor trascendencia de la época, Past and Present, en la cual se defendía una historia "desde abajo" (history from below) ${ }^{3}$. Cierto es que la escuela británica marxista no era homogénea y presentaba notables diferencias entre sus miembros, pero compartían indudablemente la aplicación del materialismo histórico en sus estudios, lo que permitía la construcción de una historia económica y social con tendencia al estructuralismo. Las ideas de esta escuela historiográfica se aplicaron en el ámbito de la historia militar en la Edad Moderna, momento en el que comienza a observarse una mayor preocupación sobre el papel del ejército dentro de la sociedad. Dentro de esta corriente debemos destacar un libro que marcaría el devenir de la historiografía naval, Guerra y decadencia de Irving Thompson ${ }^{4}$, en el cual se analizaba la estructura administrativa y la logística de la maquinaria de guerra a partir del reinado de Felipe II hasta la muerte de Felipe III. A través de la financiación y el reclutamiento, Thompson observaba que el desarrollo de los ejércitos era paralelo al de los Estados modernos, factor que trataremos más adelante. Asimismo, en su obra vislumbraba la

\footnotetext{
${ }^{1}$ Black, Jeremy, Warfare in Europe, 1650-1792, Ashgate, The International Library of Essays on Military History, 2005.

${ }^{2}$ Saavedra Vázquez, María del Carmen, "Política naval y guerra marítima en la España de Antiguo Régimen", en García Hurtado, Manuel Reyes et al. (eds.), El mar en los siglos modernos. Tomo II, Santiago de Compostela, Xunta de Galicia, 2009, p. 20.

${ }^{3}$ Aurell, Jaume et al., Comprender el pasado. Una historia de la escritura y el pensamiento histórico, Madrid, Akal, 2013, pp. 277-279.

${ }^{4}$ Thompson, Irving A. A., Guerra y decadencia: gobierno y administración en la España de los Austrias, 15601620, Barcelona, Editorial Crítica, 1981, p. 9.
} 
realidad de la marina de Habsburgo entre los siglos XVI y XVII ${ }^{5}$. A la estela de Thompson, la obra de Anderson ${ }^{6}$ reafirmaba la idea de la guerra como elemento transformador de la economía en la sociedad y en las estructuras administrativas ${ }^{7}$; al igual que Stradling ${ }^{8}$, quien continuaba la línea de Thompson aplicándola únicamente a la administración destinada a las operaciones militares de las fuerzas navales del mar del Norte; o que Goodman ${ }^{9}$, quien centra su estudio desde una perspectiva económica, con un enfoque sobre los gastos de la flota de Felipe IV y la jerarquía social presente en un navío.

En la historiografía militar española dedicada a la época moderna, hubo historiadores que aplicaron las nuevas corrientes historiográficas a los estudios militares. El caso de Alcalá Zamora y Queipo de Llano ${ }^{10}$ es paradigmático porque aplicó la metodología de Annales a los estudios militares. Lo chocante es que la escuela francesa liderada por Fernand Braudel rechazaba la historia política y militar, sin embargo, de forma original, Alcalá Zamora muestra que la historia naval no solo puede entenderse a través de la geografía, sino a partir de un análisis político que no prescinde de lo económico y social, ya que el ámbito militar es un aspecto social. Siguiendo su magisterio, encontramos la obra de Enrique Martínez Ruiz ${ }^{11}$ y Magdalena Pi Corrales ${ }^{12}$ y, más recientemente, Esteban Mira Caballos ${ }^{13}$. Ellos siguen la línea marcada por la historiografía anglosajona centrada en el ámbito militar y analizan las estructuras navales a lo largo de los siglos XVI y XVII. Pese a todo, cabe señalar que este ámbito historiográfico es muy conservador con sus métodos, con la pervivencia de un discurso tradicional muy influenciado por hitos del siglo XIX, como Cesáreo Fernández Duro ${ }^{14}$. Hay un constante designio - quizás involuntariode remarcar las glorias de las armas "españolas" a lo largo del Imperio de los Austrias hispanos — sobre todo en los trabajos de Cervera Pery ${ }^{15}$ y Hugo O’Donnell ${ }^{16}$ — y, con ello, escapar del discurso derrotista marcado por la historiografía anglosajona.

A partir de la década de los noventa, se puso en duda los grandes relatos y el materialismo histórico, iniciándose así una historia cultural más interesada en los mecanismos informales y

\footnotetext{
${ }_{5}^{5}$ Pi Corrales, Magdalena de Pazzis, "La marina de los Austria: aproximación historiográfica y perspectiva investigadora", en La historiografía de la Marina española, Madrid, Cuadernos monográficos del Instituto de Historia y Cultura Naval, 2008, p. 86.

${ }^{6}$ Anderson, Matthew Smith, Guerra y sociedad en la Europa de Antiguo Régimen: 1618-1789. Vol. 2, Madrid, Centro de Publicaciones del Ministerio de Defensa, 1990.

${ }^{7}$ García Barriga, Felicísimo, "Sociedad y conflicto bélico en la Edad Moderna: Extremadura ante la guerra con Portugal (1640-1668)", en Norba. Revista de Historia, 21 (2008), p. 30.

${ }^{8}$ Stradling, Robert, Europa y el declive de la estructura imperial española. 1580-1720, Madrid, Ediciones Cátedra, 1983.

${ }^{9}$ Goodman, David, El poderío naval español. Historia de la armada española del siglo XVII, Barcelona, Península, 2001.

${ }^{10}$ Acalá-Zamora y Queipo de Llano, José, España, Flandes y el Mar del Norte (1618-639), Madrid, Planeta, 2001.

${ }^{11}$ Martínez Ruiz, Enrique, "La batalla de Lepanto", en Ejército, 908 (2016), pp. 93-100.

${ }^{12} \mathrm{Pi}$ Corrales, Magdalena de Pazzis, España y las potencias nórdicas, "La otra invencible”. 1574. Madrid, Instituto de Historia y Cultura Naval, 1983.

${ }^{13}$ Mira Caballos, Esteban, Las armadas imperiales. La guerra en el mar en tiempos de Carlos V y Felipe II, Madrid, La Esfera de los libros, 2005.

${ }^{14}$ Fernández Duro, Cesáreo, Armada española desde la unión de los reinos de Castilla y de Aragón. Tomo IV, Madrid, Museo Naval, 1972.

${ }^{15}$ Cervera Pery, José, La estrategia naval del imperio, Madrid, Editorial San Martín, 1981.

${ }^{16}$ O'Donnell, Hugo (coord.), Historia militar de España. Tomo III: Edad moderna. Vol. I: Ultramar y la Marina, Madrid, Ministerio de Defensa, 2013.
} 
en los autores implicados en los procesos históricos. Las ideas de esta nueva interpretación se aplicaron en el ámbito de la guerra en la Edad Moderna, siendo Davide Maffi un ejemplo de ello. En la obra colectiva Guerra y sociedad en la Monarquía Hispánica, editada por Enrique García Hernán y Davide Maffi ${ }^{17}$, se refleja la aplicación de la historiografía cultural en la historia militar, con una mayor preocupación sobre la población que intervenía en las guerras mediante el reclutamiento, la jerarquía dentro del ejército y la manera en la que afectaba la violencia en la sociedad ${ }^{18}$. En la misma línea que Maffi, ubicamos la primera obra de Peter Englund ${ }^{19}$, quien realizó una visión de la batalla de Poltava a través de los relatos de los soldados que participaron en ella, remarcando el papel de la religión en las tropas momentos antes de la guerra. Del mismo modo, no podemos olvidar la contribución de Carla R. Phillips en el giro cultural de la historia militar en la época moderna. En Seis galeones para el rey de España ${ }^{20}$, la autora explica la situación naval de la monarquía mediante el asiento que obtiene Martín de Arana, cuyo propósito es el de construir seis buques para Felipe IV en un momento donde la construcción naval estaba en clara decadencia.

En los últimos años, han aparecido nuevos puntos de vista debido al enfoque a largo plazo y distante de la historia nacional, además de remarcar la aportación de la arqueología a las interpretaciones militares, modificando discursos asentados durante largo tiempo y que, gracias a las evidencias arqueológicas, se han podido rectificar. El máximo exponente de la nueva historia militar es el historiador sueco Jan Glete ${ }^{21}$, quien en varias publicaciones realiza una visión comparativa entre las distintas administraciones bélicas europeas en la época moderna, observando el nivel tecnológico, los hombres de mar, el sistema de reclutas, sus espacios de acción y cómo afectaban los cambios de los ejércitos en el desarrollo de los surgentes Estados. Esta última cuestión es central en los debates historiográficos actuales enfocados en el ámbito militar, ya que se vislumbran dos grandes vertientes. Por un lado, están los historiadores que apuestan por la denominada "Revolución Militar", es decir, aquellos que remarcan el desarrollo tecnológico a lo largo de la Edad Moderna, pero aplicados al mundo bélico. Su máximo exponente es Geoffrey Parker ${ }^{22}$, el cual analiza cómo las innovaciones armamentísticas y la introducción de la pólvora en la Europa moderna cambiaron el tradicional arte de la guerra, factor que diferenciaría al viejo continente con el asiático. En la defensa de la "Revolución Militar", subyace la idea — fruto de la reacción frente a las últimas interpretaciones — de la

\footnotetext{
${ }^{17}$ García Hernán, Enrique y Davide Maffi (eds.). Guerra y sociedad en la Monarquía Hispánica: política, estrategia y cultura en la Europa Moderna (1500-1700). Vol. 1, Madrid, Ediciones del Laberinto, Fundación Mapfre y Consejo Superior de Investigaciones Científicas, 2006.

${ }^{18}$ Quatrefages, René, "Violencia acerca de los soldados en la Corona de Castilla en el siglo XVI", en García Hernán, Enrique y Maffi, Davide. (Ed.). Guerra y sociedad... op. cit., pp. 73-97.

${ }^{19}$ Englund, Peter, La Batalla que conmocionó Europa. Poltava y el nacimiento del Imperio ruso, Barcelona, Editorial Roca, 2012.

${ }^{20}$ Rahn Phillips, Carla, Seis galeones para el rey de España. La defensa imperial a principios del siglo XVII, Madrid, Alianza Editorial, 1991.

${ }^{21}$ Glete, Jan, Warfare at sea, 1500-1650. Maritime conflicts and the transformation of Europe, Londres, Routledge, 2000; Glete, Jan, War and the state in early modern Europe: Spain, the Dutch Republic and Sweden as fiscalmilitary states, Londres, Routledge, 2002. DOI: https://doi.org/10.4324/9780203465318.

${ }_{22}$ Parker, Geoffrey, La revolución militar y apogeo de occidente. 1500-1800, Madrid, Alianza Editorial, 2001.
} 
necesidad de retornar al estudio de los ejércitos y armadas y, sobre todo, su principal propósito, la guerra. Los autores militares de esta corriente defienden que no se puede comprender la dinámica de las potencias políticas de la época moderna únicamente desde un punto de vista económico y social, sino que es necesario recordar la innovación tecnológica y su aplicación en la batalla ${ }^{23}$.

Por otra parte, está la corriente que defiende la idea del Estado fiscal-militar, es decir, una interpretación que relaciona el proceso de modernización en los ejércitos con el desarrollo de los nacientes europeos a través del sistema administrativo y fiscal. Como mencionábamos anteriormente, Jan Glete - junto a Hanlon - es el mayor exponente de esta idea, aunque ya podemos ver ciertas pinceladas en Guerra y decadencia de Thompson. Esta tendencia defiende que, debido al exponencial esfuerzo bélico en la época moderna, los ejércitos —incluidas las armadas - sufren un desarrollo tecnológico que requiere gran cantidad de recursos, un capital al que únicamente pueden hacer frente unos Estados paulatinamente más centralizados. Para mantener tal maquinaria de guerra eran necesarios cambios en la administración de los reinos europeos y una mayor presión fiscal. Por tanto, la tendencia defendida por Glete es que el desarrollo de los ejércitos en la época moderna provocó cambios paralelos en los reinos y los reorientaron hacia el horizonte del Estado moderno.

\section{Situación del poder naval durante el reinado de Felipe IV}

El mar fue un espacio vital para comprender el equilibrio de poderes entre los reinos europeos, ya que dominar dicho espacio marítimo significaba someter a los enemigos tanto a nivel marítimo como terrestre. El poder hegemónico de la monarquía no se conformaba únicamente por el volumen real de embarcaciones y ejércitos que poseía (fuerzas reales ${ }^{24}$ ), sino que también debemos advertir la presión que ejercía la posesión de los recursos militares sobre otros reinos, un potencial naval y militar que afectaba en la diplomacia y el prestigio de la Corona (fuerzas aparentes ${ }^{25}$ ). Un triunfo o una derrota militar iba más allá de la destrucción de los recursos del enemigo. Con la victoria, la monarquía mantenía un prestigio psicológico con el cual atemorizar al enemigo y persuadir al aliado ${ }^{26}$. Por ello, podemos afirmar que la guerra era un símbolo de fortaleza y prestigio, a la vez que un instrumento para la integridad de los territorios monárquicos. El control sobre el mar era una idea clave muy presente en la obra de

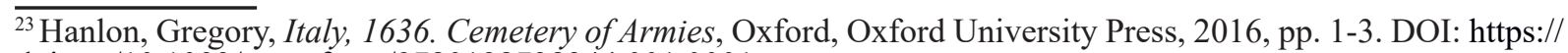
doi.org/10.1093/acprof:oso/9780198738244.001.0001.

${ }^{24}$ Goodman, David., El poderío naval... op. cit., pp. 7-8.

${ }^{25}$ Ibídem, pp. 7-8

${ }^{26}$ Ibídem, p. 9.
} 
Giovanni Botero, Ragioni di Stato ${ }^{27}$, donde se afirmaba que dominar el mar significaba controlar el ámbito terrestre. Siguiendo una reflexión del profesor Pablo Fernández Albaladejo, con la que empatizo, al realizar una visión general sobre los diferentes capítulos de la Historia, podemos apreciar que en pocas ocasiones un régimen político ha sido capaz de combinar la dominación del ámbito marítimo y el continente europeo. No obstante, según el profesor Goodman, las ideas de Botero influenciaron en el pensamiento político del primer valido de Felipe IV, sobre todo aquellas reflexiones que hacían referencia a la necesidad de un Imperio y su poder naval, ya que una monarquía tan extensa no podía subsistir sin la ayuda mutua entre los reinos unidos ${ }^{28}$. El planteamiento de Botero tuvo su reflejo en uno de los hombres encargados de las armadas del rey Felipe III, el conde de Godomar, quien advertía del crecimiento naval de otras potencias como Inglaterra, y como esto suponía un peligro para la integridad de la monarquía. Lo mismo ocurrió con Martín de Aróztegui, quien defendía lo siguiente:

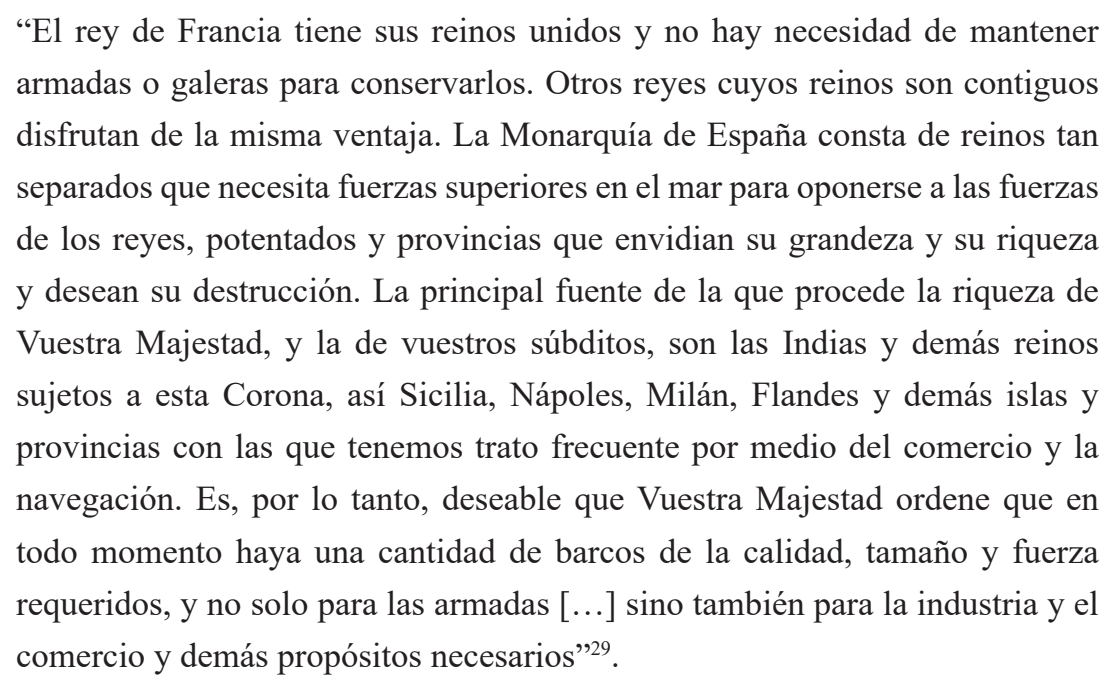

La advertencia sobre el peligro francés se repetiría en 1636, en una reunión del Consejo de Estado, la cual trataba la grave amenaza de las fuerzas francesas sobre Cerdeña ${ }^{30}$. Tras la muerte de Felipe III, tuvo lugar la proclamación de su hijo de dieciséis años, Felipe IV. "Un rey que reina, pero no gobierna", dependiente de su hombre de confianza, Gaspar de Guzmán, conde de Olivares. Al obtener el favor del príncipe en el ámbito privado de palacio, el valido se convirtió en la figura que realmente llevaba las riendas del gobierno de un Imperio. El valido intentó llevar a cabo una serie de reformas y, con ello, retornar a la tradición imperial, fundamento propio de la monarquía, y alejarse de la política derrotista ${ }^{31}$. Con la llegada del nuevo rey, había un cierto entusiasmo en la mejora del "reino enfermo" y, para ello, era necesario la recuperación de los recursos navales de la monarquía. Las armadas del rey católico habían disminuido

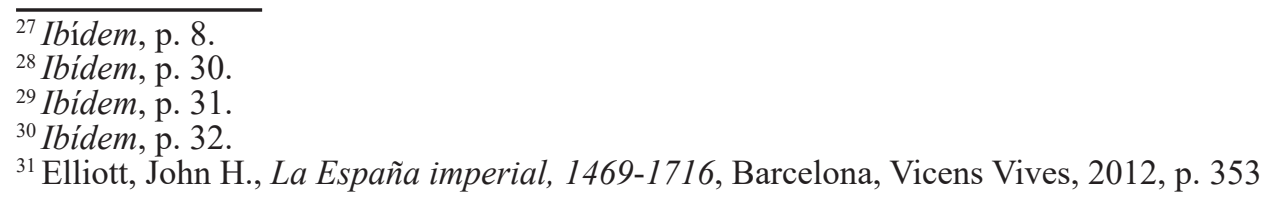


considerablemente durante los últimos años de Felipe III, lo que provocó una disminución del comercio marítimo y una mayor presencia holandesa en los territorios ultramarinos portugueses y castellanos ${ }^{32}$. Olivares opinaba que debía fortalecerse la Armada y favorecer a los hombres de $\operatorname{mar}^{33}$. Ante la situación deteriorada de las armadas, el valido creó la Junta de Armadas en $1622^{34}$ — dentro de su línea política de creación de Juntas_- dirigida por él mismo y conformada por antiguos componentes de la Armada durante el anterior reino, como don Diego Brochero, don Fernando Girón, o don Juan de Pedroso ${ }^{35}$. La Junta de Armadas favoreció las licencias de corso en el mar del Norte — estableciéndose las bases en Dunquerque y Gravelinas - con el objetivo de atacar el comercio holandés, el cual se creía que era el pulmón económico de las provincias rebeldes. La Junta de Armadas impulsó a su vez los contratos navales entre particulares y la Corona para abaratar, teóricamente, los gastos de construcción y favorecer el incremento de los recursos navales de la monarquía; asimismo, intentó crear compañías comerciales a semejanza de los territorios del norte de Europa, como fue el caso de la Real Junta del Almirantazgo (16241628). Dicha institución se componía por comerciantes flamencos y germanos establecidos en Sevilla, los cuales aportaban su capital para reactivar el comercio $^{36}$. Un prototipo de política mercantilista con el fin de restringir el comercio holandés y mejorar la deficitaria balanza comercial de la monarquía ${ }^{37}$.

\subsection{El prestigio y la guerra preventiva}

En el inicio del reinado de Felipe IV, su valido se hizo con el mando de la política imperial con el fin de aspirar a la hegemonía mundial de la casa de Austria $^{38}$. La Monarquía Hispánica se había convertido en el árbitro de Europa, lo cual provocaba un esfuerzo bélico cada vez más intenso que requería más recursos financieros. La idea de la Pax Hispánica durante el reinado de Felipe III era una ilusión, ya que realmente fue una época de paz obligada debido a la escasez de recursos de la monarquía, fruto de las obligaciones bélicas del imperialismo del emperador Carlos y su hijo Felipe. El conde-duque de Olivares era consciente de que el Imperio era "cautivo" de sus necesidades bélicas ${ }^{39}$, las cuales mermaban no solo a los pecheros castellanos, sino también a los otros reinos ${ }^{40}$. No solo aumentaban los costes de guerra de las acciones

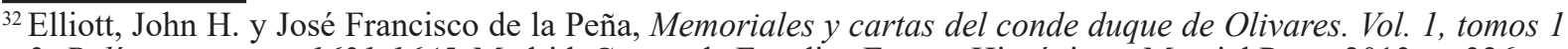
y 2: Política interior: 1621-1645, Madrid, Centro de Estudios Europa Hispánica y Marcial Pons, 2013, p. 326.

${ }^{33}$ Ibidem, p. 327.

${ }^{34}$ Rivero Rodríguez, Manuel, La monarquía de los Austrias, Historia del Imperio español, Madrid, Alianza Editorial, 2017, p. 231.

${ }^{35}$ Elliott, John H. y José Francisco de la Peña, Memoriales y cartas... op. cit., p. 326.

${ }^{36}$ Díaz González, Francisco Javier, "La creación de la Real Junta del Almirantazgo (1624-1628)", en Espacio, Tiempo y Forma. Serie IV: Historia Moderna, 12 (1999), p. 91.

${ }^{37}$ Aragón Ruano, Álvaro, "Las compañías de comercio armado durante el siglo XVII: los proyectos de 1667 y 1668”, en Obradoiro de Historia Moderna, 25 (2016), p. 176.

${ }^{38}$ Rivero Rodríguez, Manuel, La monarquía de... op. cit., p. 239.

${ }^{39}$ Ibídem.

${ }^{40}$ Tracy, James D., "War Finance and Fiscal Devolution in Charles V's Realms", en Blockmans, Wim y Nicolette Mout, The World of Emperor Charles V, Amsterdam, Koninklijke Nederlandse Akademie van Wetenschappen
} 
ofensivas, sino que el mantenimiento de un sistema defensivo para conservar los territorios del rey ${ }^{41}$ se acrecentaba a un ritmo superior a los ingresos reales ${ }^{42}$. El Consejo de Hacienda demostraba que mantener el ejército de Flandes en tiempos de paz era igual o más costoso que en tiempos de guerra ${ }^{43}$. Por ello, no era lógico continuar una paz costosa que ponía en duda el poder de los Habsburgo hispanos.

La reputación de las armas "españolas" y el poder de la Corte eran dos pilares de la conservación del Imperio ${ }^{44}$. Las derrotas menguaban la credibilidad y capacidad militar del rey católico, sobre todo la triunfante imagen en torno a los tercios viejos y el temor que provocaba, elemento disuasorio en la política de la monarquía. No existía una "mala paz" porque significaba la pérdida del Imperio ${ }^{45}$. Si las Provincias Unidas rebeldes conseguían vencer al "Rey planeta", ¿por qué no podrían conseguirlo otros enemigos? ${ }^{46}$ No era posible abandonar los gastos imperiales, ni pactar demostrando la debilidad de un "reino enfermo". Por ello, en los años iniciales del rey Felipe IV se optó por la guerra preventiva, es decir, actuar antes que el adversario para provocar que este centre sus recursos en el espacio que decida el atacante. Esta táctica realmente era una "guerra defensiva", ya que se basaba en acometer y enfocar la guerra en "el baluarte", Flandes, para liberar el resto de los territorios de los ataques holandeses, especialmente las posesiones portuguesas, ya que los recursos de las Provincias se destinarían en la defensa más que en la expansión. En resumen, una guerra preventiva con el objetivo de defender la integridad de la monarquía ${ }^{47}$.

La reputación de la monarquía debía retornar por la vía marítima ${ }^{48}$. En un contexto de guerra en el continente europeo, la fecha en la que debía finalizar la tregua de 1609 era cercana. Ante la nula descendencia del matrimonio de Isabel Clara Eugenia y el archiduque Carlos, los Países Bajos retornaban de forma directa a la Corona católica ${ }^{49}$. La voluntad de no modificar el cierto equilibrio existente en dicho territorio, además de insertarlo dentro del "armazón político de la monarquía" ${ }^{50}$, no encajaba con la realidad ultramarina. Las ocupaciones holandesas en América y el Índico, así como el contrabando, eran una gran amenaza a la estabilidad y la seguridad del comercio portugués y castellano ${ }^{51}$. Por ello, prolongar la tregua no parecía favorable a los intereses comerciales ibéricos.

\footnotetext{
Verhandelingen, 2000, p. 22.

${ }^{41}$ Rivero Rodríguez, Manuel, La monarquía de... op. cit., p. 240.

${ }^{42}$ De Carlos Morales, Carlos Javier, "El precio del dinero dinástico: endeudamiento y crisis financieras en la España de los Austrias, 1557-1647”, en Estudios de Historia Económica, 70 (2016), p. 24.

${ }^{43}$ Elliott, John H., La España imperial... op. cit., p. 354.

${ }^{44}$ Rivero Rodríguez, Manuel, La monarquía de... op. cit., p. 239.

${ }^{45}$ Ibídem.

${ }^{46}$ Kennedy, Paul M., Auge y caída de las grandes potencias, Madrid, Debolsillo. Para este trabajo se ha utilizado la versión inglesa: Kennedy, Paul M., The rise and fall of the great powers, economic change and military conflict from 1500 to 2000, Nueva York, Vintage Books, 2006, p. 51.

${ }^{47}$ Rivero Rodríguez, Manuel, La monarquía de ... op. cit., p. 238.

${ }^{48}$ Alonso Acero, Beatriz, "Defensa del Mediterráneo: escenarios, objetivos y estrategias”, en O’Donnell, Hugo (coord.), Historia militar de España ... op. cit., p. 247.

${ }^{49}$ Rivero Rodríguez, Manuel, La monarquía de ... op. cit., p. 238.

${ }^{50}$ Fernández Albaladejo, Pablo, La crisis de la Monarquía, Barcelona, Crítica, 2009, p. 122.

${ }^{51}$ Rivero Rodríguez, Manuel, La monarquía de... op . cit., p. 238.
} 
Ya a finales del siglo XVI, algunos consejeros de Felipe III, como Baltasar Álamos de Barrientos o Juan de Mariana, advertían de la necesidad de realizar una contraofensiva en el norte para asegurar la tradición imperialista de la monarquía. Era necesario potenciar la influencia en el mar del Norte al mismo tiempo que se protegía el caudal de plata procedente de las Indias ${ }^{52}$. Un elemento principal entre los arbitristas de la época era la idea de "guerra defensiva por tierra y ofensiva por mar"53, aspecto que Olivares trató de incentivar mediante un aumento de los recursos navales para defender el Imperio ${ }^{54}$. Tras el fin de la tregua, se inició la guerra preventiva por mar. Mientras que los barcos holandeses eran expulsados de la Península Ibérica, y algunos de ellos eran apresados por la Armada del Estrecho, la reforzada Armada de Flandes fijó sus ataques en los navíos comerciales holandeses. Al no poder realizar enfrentamientos directos con grandes armadas, las flotas del norte se dedicaron a asaltar pequeñas embarcaciones o convoyes con escasa protección ${ }^{55}$. Desde Madrid se afirmaba que, atacando el comercio holandés — verdadero pulmón económico de los rebeldes - se conseguiría eclipsar sus recursos económicos necesarios para la guerra terrestre. Uno de los objetivos más concretos eran los pescadores dedicados al arenque, industria importante en el mar del Norte ${ }^{56}$. Asimismo, ante la falta de embarcaciones de propiedad regia, se incentivaron los asientos navales entre particulares y la Corona, a la vez que se restituyó un sistema muy eficaz en el Mediterráneo, el corso. En la Ordenanza del 24 de diciembre de 1621, Felipe IV legalizaba el corso "contra turcos, moros y moriscos como contra los rebeldes de las islas de Holanda y Zelanda" 57 . El corso era una cierta vía de "privatización" de la acción armada frente a los rebeldes, una búsqueda de desgastar el comercio holandés ${ }^{58}$ y provocar un desvío de sus recursos ofensivos hacia la protección de sus navíos. A la vez, los precios de las mercancías holandesas se elevaron considerablemente debido al aumento de fletes y seguros ${ }^{59}$, provocando una mayor concentración de navíos a través del sistema de convoy y reduciendo el flujo comercial. Con sede en Dunquerque y Ostende, los corsarios españoles y flamencos obtenían grandes beneficios en su caza de mercantes y pesqueros del mar del Norte. Según algunos autores ${ }^{60}$, en este contexto los botines del corso hispano flamenco fueron superiores (cinco veces mayor) a los obtenidos por los holandeses en sus ataques navales, con un total de 1880 capturas entre 1629 y $1638^{61}$. A ello hay que añadir las palabras del armador Martín de Justiz, quien afirmaba en 1632 que "los navíos holandeses que antes navegaban a la costa de Francia

\footnotetext{
${ }_{52}$ Stradling, Robert, La Armada de Flandes. Política naval española y guerra europea. 1568-1668, Madrid, Cátedra, 1992, p. 45.

${ }^{53}$ Alcalá-Zamora y Queipo de Llano, José, España, Flandes y ... op. cit., p. 77.

${ }^{54}$ Rahn Phillips, Carla, Seis galeones para... op. cit., p. 41.

${ }^{55}$ Alcalá-Zamora y Queipo de Llano, José, España, Flandes y ... op. cit., p. 77.

${ }^{56}$ Stradling, Robert, La Armada de... op. cit., p. 49.

${ }^{57}$ Alcalá-Zamora y Queipo de Llano, José, España, Flandes y el... op. cit., p. 77.

${ }^{58}$ Alonso Acero, Beatriz, "Defensa del Mediterráneo..." op. cit., p. 248.

${ }^{59}$ Alcalá-Zamora y Queipo de Llano, José, España, Flandes y ... op. cit., p. 77.

${ }^{60}$ Rahn Phillips, Carla, Seis galeones para... op. cit., p. 35; Alcalá-Zamora y Queipo de Llano, José, España, Flandes y ... op. cit., p. 133.

${ }^{61}$ Otero Lana, Enrique, "El corso del Flandes español como factor de guerra económica", en Studia histórica. Historia Moderna, 27 (2005), p. 122.
} 
con 6 hombres, hoy los navegan con 18 y aún con otros de guerra de escolta, con que se les han bajado las ganancias" ${ }^{\circ}$.

Por otra parte, la Armada de Flandes fue potenciada a partir de 1621, aunque tardó en causar problemas a los holandeses debido a contrariedades de coordinación entre Bruselas y Madrid $^{63}$. En 1625, tras el fracaso inglés en Cádiz, la Armada de Flandes estaba liberada de la posible presencia inglesa en el canal de La Mancha, por lo que pudo realizar numerosas capturas de flotas pesqueras en colaboración con los corsarios. Advirtiendo las limitaciones de la Armada, los resultados de esta política naval fueron más que notables, ya que capturaron un gran número de embarcaciones, a la vez que rompían en ocasiones el sistema comercial de la Compañía holandesa de las Indias Occidentales ${ }^{64}$. El desgaste provocado por este tipo de guerra llevó a que el comercio de las Provincias Unidas cayera mientras su deuda dinástica aumentaba. No obstante, la edad de oro de la Armada de Flandes finalizó tras el inicio de la guerra con Francia (1635) y las sublevaciones del Reino de Portugal y el Principado de Cataluña. Cierto es que hubo un último gran intento marítimo con el objetivo de romper el bloqueo francés, suministrar armas y recursos a las tropas de Flandes tras la ruptura del "Camino español" y eliminar las escuadras holandesas. Sin embargo, era un plan muy ambicioso que fracasó en la última parte, ocasionando la derrota de la Armada en la batalla de Las Dunas (1639). Ante la posibilidad de desmembración de la monarquía, gran parte de los recursos de la Armada de Flandes se destinaron a "apagar el incendio" de la Península Ibérica, gran parte de las fragatas y galones del norte retrocedieron hasta las costas del corazón de la monarquía. Este cambio de política marítima refleja cuáles eran las preocupaciones de la Corte de Madrid y cómo dejaron en un segundo plano la rebelión de las Provincias Unidas.

\section{La monarquía y la defensa naval de Portugal}

Tras el fracaso de la Empresa de Inglaterra de 1588, llegaron las primeras amenazas holandesas e inglesas al océano Índico, concretamente al Estado da Índia. Según su correspondencia, los virreyes de Goa reflejaban su preocupación por "los enemigos de Europa"65 en aguas asiáticas, ya que el Índico portugués no poseía un sistema defensivo militar, sino que más bien era un control comercial sobre puntos estratégicos, centrados en la producción y distribución. A inicios del siglo XVII, las rentas de las posesiones ultramarinas portuguesas eran

\footnotetext{
${ }^{62}$ Ibidem, p. 123.

${ }^{63}$ Ibídem, p. 125.

${ }^{64}$ Ibidem, p. 126.

${ }^{65}$ Parker, Geoffrey, La revolución militar... op. cit., pp. 144-145.
} 
insuficientes para hacer frente a los gastos civiles y militares del virreinato de Goa ${ }^{66}$. Reflejo de ello fueron las crecientes incursiones inglesas y holandesas en el circuito índico, sobre todo, tras la creación de la Compañía Holandesa de las Indias Orientales (Vereenigde Oostindische Compagnie, VOC $)^{67}$. Dicha compañía, creada en 1602, controlaba el comercio desarrollado entre el este del cabo de Buena Esperanza hasta el estrecho de Magallanes. Los denominados Diecisiete Señores administraban, dirigían, organizaban e invertían el capital de la Compañía ${ }^{68}$. Con la estabilidad financiera inicial y el éxito económico, el capital alcanzó unas cifras muy elevadas en comparación con el resto de sociedades existentes. Con dicho poder económico, la Compañía de las Indias Orientales se convirtió en una importante institución, una especie de "Estado dentro del Estado"69, capaz de presionar al Gobierno o declarar la guerra según sus intereses económicos gracias a la disposición que tenían de una fuerza militar. La presencia de dicha Compañía en el Índico produjo graves problemas a las posesiones portuguesas, como, por ejemplo, los ataques a Goa, Ormuz, Cochin, etc. ${ }^{70}$. El potencial económico de la Compañía era tal, que consumieron aproximadamente quince millones de florines en su expansión comercial y territorial por el decadente Imperio luso ${ }^{71}$. Asimismo, la red de factorías ya no era rentable como en el siglo XVI, y los beneficios del comercio de las especias se habían trasladado al Atlántico. Como compensación del decadente comercio oriental, el mercado portugués se había centrado en el triángulo comercial de esclavos y azúcar ${ }^{72}$ entre Angola, Brasil y Lisboa, a partir de los cuales obtenía los principales beneficios, reorientando de esta manera los objetivos comerciales y estratégicos del reino portugués ${ }^{73}$.

La protección militar que otorgaba Felipe II en el momento de la unión de coronas (1580) ya no era visible para los mercaderes de Lisboa. Mientras que los peligros del comercio oriental provenían del Gran Turco, la amenaza del comercio atlántico e índico provenía de las Provincias Unidas, convirtiendo a la Monarquía Hispánica en la causa bélica y el problema en vez de una garantía $^{74}$. El fin de la tregua en el norte y la restauración del imperialismo castellano eran vistos como un lastre para el comercio portugués, el cual se veía afectado por el supuesto abandono de intereses por parte de la Corte, además de verse amenazado por los enemigos de Felipe IV ${ }^{75}$. Durante el gobierno de Olivares, la idea de incapacidad militar de la monarquía se acrecentó tras la pérdida de la flota en Matanzas y la ocupación holandesa de Bahía de San Salvador. A pesar de que se hizo un esfuerzo bélico de gran envergadura al reunir una Armada bajo el

\footnotetext{
${ }^{66}$ Rivero Rodríguez, Manuel, La monarquía de... op. cit., p. 254.

${ }^{67}$ Neal, Larry, "Las acciones de la Compañía holandesa de las Indias Orientales", en Goetzmann, William N. y Geert Rouwenhorst (coords.), Los origenes de las finanzas: las innovaciones que crearon los modernos mercados de capitales, Madrid, Empresa Global, 2007, pp. 182-193.

${ }^{68}$ Alonso García, David, Mercados y mercaderes en los siglos XVI y XVII, Madrid, Síntesis, 2016, p. 90.

${ }^{69}$ Ibídem, p. 90.

${ }^{70}$ Rivero Rodríguez, Manuel, La monarquía de... op. cit., p. 254.

${ }^{71}$ Parker, Geoffrey, La revolución militar... op. cit., p. 147.

${ }^{72}$ Elliott, John H., La España imperial... op. cit., p. 368.

${ }^{73}$ Rivero Rodríguez, Manuel, La monarquía de... op. cit., p. 254.

${ }^{74}$ Ibidem, p. 252.

${ }^{75}$ Parker, Geoffrey, La revolución militar... op. cit., p. 149.
} 
mando de Fabrique de Toledo para recuperar el territorio ${ }^{76}$, no fue suficiente para conciliar a los comerciantes y dirigentes lusos. La incapacidad defensiva de los intereses portugueses por parte de Felipe IV se volvió a evidenciar tras la toma de Pernambuco y Curaçao por los holandeses.

Bajo mi punto de vista, y siguiendo las ideas de Manuel Rivero y Rafael Valladares ${ }^{77}$, a diferencia de la visión nacionalista propia del siglo XIX, que analizaba la independencia portuguesa como una defensa de las libertades lusas frente al proyecto de Olivares con el fin de castellanizar el Imperio luso, creo que hay mayores evidencias de que la ruptura entre el reino portugués y el "rey planeta" se produjo por la desconexión entre la élite portuguesa — con sus intereses comerciales y políticos- y la Corte de Felipe IV. Una ruptura de intereses que se refleja a la perfección en el espacio marítimo, fruto de la incapacidad militar de la monarquía por defender los objetivos portugueses, reorientados hacia el Atlántico durante finales del siglo XVI e inicios del siglo XVII. Ya prescindían de la protección castellana.

\section{Conclusión}

Aunque el presente trabajo no tenía como objetivo centrarse en grandes batallas navales, sí creo necesario destacar la batalla de Salvador de Bahía (1625), la cual tuvo gran relevancia y sirvió como ejemplo del proyecto de Olivares, la Unión de Armas. A través de la solidaridad militar entre portugueses y castellanos ${ }^{78}$, Olivares quería demostrar cómo la monarquía podía vencer a los enemigos, en este caso, reconquistando Bahía de Todos los Santos a las Provincias Unidas. Por ello, el cuadro de Maíno La recuperación de Bahía de Todos los Santos ${ }^{79}$ se convirtió en símbolo de la afirmación de la Unión de Armas. Tal fue la repercusión de la citada batalla, que hubo una serie de conmemoraciones en Madrid con obras de Lope de Vega y Antonio Correa ${ }^{80}$, donde se narraban los acontecimientos junto a una serie de emblemas y figuras que creaban una memoria histórica de la Península Ibérica, y sus hazañas bélicas ${ }^{81}$. A su vez, se publicaron una serie de relatos breves, escritos por soldados, e importantes y extensos volúmenes, entre los cuales destaca el libro del padre Bartolomeu Guerreiro, Jornada dos Vassallos da Coroa de Portugal. El jesuita portugués, muy crítico con el olvido de los intereses portugueses por parte del rey católico, ofrece una detallada crónica sobre quienes componían la Armada, el

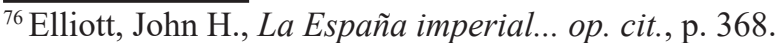

${ }_{77}$ Valladares, Rafael, "La política de Olivares y Portugal”, en Libros de la Corte, 5 (2012), pp. 107-108.

${ }^{78}$ Peres, Lygia Rodrigues Vianna, "El Brasil Restituido de Lope de Vega y La pérdida y restauración de la Bahía de Todos Los Santos, de Juan Antonio Correa. Historia, Emblemática”, en Estudios del teatro áureo: Texto, espacio y representación, México, Universidad Nacional Autónoma Metropolitana, 2003, p. 245.

${ }_{79}^{79}$ Maíno, Juan Buatista, La recuperación de Bahía de Todos los Santos, 1634-1635, Museo del Prado, Madrid.

${ }^{80}$ Ziller Camenietzki, Carlos y Gianriccardo Grassia Pastore, "1625, o Fogo e a Tinta: a batalha de Salvador nos relatos de guerra", en Topoi, vol. 6, 11 (2005), p. 266.

${ }^{81}$ Peres, Lygia Rodrigues Vianna, “El Brasil Restituido...” op. cit., p. 261.
} 
apoyo financiero portugués, las rutas y los acontecimientos bélicos ${ }^{82}$. Lo importante de dicha obra es la visión que ofrece de Castilla y Portugal como dos reinos vasallos del mismo rey, sin preeminencia de ninguna sobre el otro ${ }^{83}$.

Muchas cuestiones surgieron al realizar este trabajo, sin embargo, la principal interrogativa era si realmente hubo una política naval incluida en la supuesta gran estrategia del condeduque de Olivares. Según Geoffrey Parker ${ }^{84}$, y su discípulo Paul C. Allen, desde el reinado de Felipe II existía una gran estrategia de ambiciones globales por parte de la rama hispana de los Habsburgo. Un proyecto de monarquía universal, heredado del emperador Carlos V, que condicionaría las futuras ambiciones de los reyes castellanos. Bajo mi punto de vista $-\mathrm{y}$ a raíz de la obra de Kennedy ${ }^{85}$ - , podemos llegar a la conclusión de la inexistencia de una gran estrategia universal durante el reinado de Felipe IV. En lo concerniente a nuestro trabajo, cierto es que hay un impulso inicial a los recursos navales con el objetivo de defender el Imperio, ya sea protegiendo las flotas indianas o debilitando el comercio holandés del mar del Norte. Sin embargo, analizando el resto de las actuaciones de las armadas, se refleja el grado de improvisación en la política exterior de Olivares, quien actuó según las necesidades y amenazas del momento. Un claro ejemplo de la ausencia del horizonte universal planteado por Parker, y la inexistencia de unas prioridades navales, es el auxilio hispano a los franceses en la isla de Ré, tras el ataque inglés en 1627, cuando un año más tarde, la Flota de Indias fue capturada por el capitán neerlandés Piet Heyn. Asimismo, en 1635 se inicia una guerra entre el reino de Francia y la Monarquía Católica, apostando esta última por una actitud defensiva en el espacio marítimo, sobre todo, tras la derrota de las galeras genovesas frente a la fortalecida Armada francesa en 1650.

Por tanto, más que establecer la idea de la gran estrategia, podemos defender la visión de una monarquía en constante guerra, fruto de su naturaleza imperial, en defensa del derecho establecido, la religión católica y los límites del Imperio. Una simbiosis entre jurisdicción, religión, la defensa de la casa de Austria y razón de Estado.

\footnotetext{
$\overline{{ }^{82} \text { Ibidem, p. } 256 .}$

${ }^{83}$ Ziller Camenietzki, Carlos y Gianriccardo Grassia Pastore, “1625, o Fogo...” op. cit., p. 262.

${ }^{84}$ Parker, Geoffrey, La gran estrategia de Felipe II, Madrid, Alianza Editorial, 1999, pp. 31-36.

${ }^{85}$ Kennedy, Paul M., Auge y caída... op. cit.
} 